02

\title{
Влияние режимов импульсного лазерного отжига на оптические свойства кремния, гипердопированного селеном
}

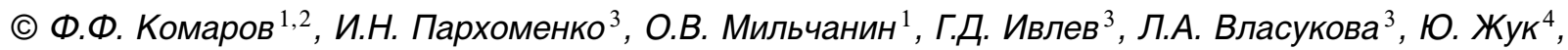 \\ А.А. Цивако ${ }^{5}$, Н.С. Ковальчук ${ }^{1}$
}

${ }^{1}$ Научно-исследовательское учреждение Институт прикладных фризических проблем им. А.Н. Севченко

Белорусского государственного университета,

220045 Минск, Республика Беларусь

${ }^{2}$ Научно-исследовательский технологический университет „МИСиС“,

119049 Москва, Россия

${ }^{3}$ Белорусский государственный университет,

220030 Минск, Республика Беларусь

${ }^{4}$ Университет М. Кюри-Склодовской,

20-031 Люблин, Польша

${ }_{5}^{5}$ ОАО „Интеграл“,

220108 Минск, Республика Беларусь

e-mail: komarovf@bsu.by

Поступила в редакцию 12.04.2021 г.

В окончательной редакции 20.04.2021 г.

Принята к публикации 23.04.2021 г.

Слои кремния, легированные селеном до концентраций $4-6 \cdot 10^{20} \mathrm{~cm}^{-3}$, что на 4 порядка величины превышает предел равновесной растворимости этой примеси, получены ионной имплантацией с последующим импульсным лазерным отжигом (ИЛО) при плотностях энергии в импульсе $W=0.55,0.8,1.0,1.5$, 2.0 и $2.5 \mathrm{~J} / \mathrm{cm}^{2}$. Методом обратного резерфордовского рассеяния ионов гелия показано, что до $60-70 \%$ внедренной примеси находится в позиции замещения в решетке кремния. Слои, гипердопированные селеном, проявляют существенное поглощение (36-40\%) в области длин волн $1100-2400 \mathrm{~nm}$. Проведено сравнение спектров поглощения слоев кремния в зависимости от режимов лазерного отжига. Показано, что отжиг при $W=2.0 \mathrm{~J} / \mathrm{cm}^{2}$ является оптимальным с позиции максимального структурного совершенства гипердопированных слоев кремния. Данный фактор очень важен для применений сформированных структур в фотодетекторах и элементах солнечной энергетики. В то же время поглощение в видимом и ближнем ИК диапазонах длин волн достигает максимального значения после отжига при $W=1.0 \mathrm{~J} / \mathrm{cm}^{2}$ и практически не меняется при дальнейшем увеличении плотности энергии в импульсе.

Ключевые слова: кремний, гипердопирование, имплантация селена, лазерный отжиг, примесная подзона, поглощение и отражение света.

DOI: $10.21883 / \mathrm{OS} .2021 .08 .51199 .2158-21$

\section{Введение}

В последние десятилетия кремниевая фотоника, как одна из лидирующих технологических платформ крупномасштабного интегрирования многофункциональных оптических и электронных систем, привлекает пристальное внимание из-за низкой стоимости, а также сверхплотной и компактной упаковки элементной базы. В интегрированных приборах кремниевой фотоники детекторы должны обладать способностью регистрировать фотоны с длиной волны более чем $1.1 \mu \mathrm{m}$, которые могут распространяться с минимумом потерь внутри оптоволокна или иных волноводных сред. Энергия таких фотонов меньше ширины запрещенной зоны $\left(E_{g}\right) \mathrm{Si}(1.12 \mathrm{eV})$. Кремний - основной материал микроэлектроники, но пока значительно реже используется в оптоэлектронике, так как является непрямозонным полупроводником с указанной выше величиной $E_{g}$. Вследствие этого кремниевые солнечные батареи пропускают инфракрас- ную (ИК) часть солнечного спектра $\sim(1.1-3) \mu \mathrm{m}$, что составляет около $30 \%$ общего потока солнечной энергии [1], а кремниевые фотодетекторы нечувствительны в области трех основных полос оптоволоконных телекоммуникационных систем: $S(1460-1530) \mathrm{nm}$, $C(1530-1565) \mathrm{nm}$ и $L(1565-1625) \mathrm{nm}$ [2]. Для решения данных проблем ведется активный поиск недорогих и эффективных ИК фотодетекторов, совместимых с кремниевой КМОП-технологией (КМОП - комплементарная структура металл-оксид-полупроводник). К настоящему времени установлено, что наибольший коэффициент поглощения света в ИК диапазоне при комнатной температуре $\left(\sim 10^{4} \mathrm{~cm}^{-1}\right)$ наблюдается у монокристаллического кремния, пересыщенного атомами халькогенов (S, Se, Te) [3].

Равновесная растворимость халькогенов в кремнии составляет $\sim 10^{16} \mathrm{~cm}^{-3}$. При таких концентрациях атомов халькогенов создаются глубокие уровни в запрещённой 
зоне кремния. Однако при превышении равновесной растворимости на 4-5 порядков примесные уровни сливаются в подзону. Становится возможным поглощение фотонов через электронные переходы „валентная зона-примесная подзона““и „примесная подзона-зона проводимости“ [4]. Чтобы добиться гиперпересыщения, легирование кремния халькогенами проводят с использованием неравновесных методов, таких как ионная имплантация с последующим фемто-, пико-, наносекундным лазерным [3,5,6] или флэш-отжигом [7].

В 1961 г. Шокли и Куизер показали, что теоретический предел эффективности кремниевых солнечных батарей составляет 30\% [8]. Позже, используя тот же подход, авторы работы [9] показали, что теоретический предел эффективности солнечных батарей на основе модифицированного кремния с примесной подзоной можно значительно увеличить. Таким образом, предельная эффективность солнечных батарей на основе кремния, пересыщенного халькогенами, может быть существенно выше, чем для классических кремниевых батарей.

Следует отметить, что для дальнейшей миниатюризации кремниевых электронных устройств необходимо получить кремний со сверхвысокими концентрациями свободных электронов $10^{21} \mathrm{~cm}^{-3}$ [10]. В настоящее время высокую концентрацию свободных электронов получают легированием кремния примесями, создающими мелкие уровни в запрещенной зоне кремния (например, элементами V группы Периодической системы: P, As и $\mathrm{Sb})$. У этих примесей небольшая энергия активации (20-50 meV), малый коэффициент диффузии и достаточно большой предел равновесной растворимости в кремнии. Однако даже при легировании кремния этими примесями до концентраций, превышающих равновесный предел растворимости, не удается получить концентрацию свободных электронов выше $\sim 5 \cdot 10^{20} \mathrm{~cm}^{-3}[11]$. Недавно установлено, что примеси (например, халькогены), создающие в кремнии глубокие уровни с энергией ионизации в несколько сотен $\mathrm{meV}$, могут индуцировать свободные электроны в кремнии до концентраций значительно выше $10^{20} \mathrm{~cm}^{-3}$ [7]. При определенных концентрациях процесс сопровождается так называемым переходом „изолятор-проводник“, когда примесная подзона перекрывается с зоной проводимости [12]. При этом концентрация свободных электронов линейно возрастает с увеличением концентрации примеси, а доля электрически активированной примеси (находящейся в узлах решётки $\mathrm{Si}$ ) остаётся практически неизменной [7]. В работе [13] показано, что $\mathrm{Si}$, гиперпересыщенный теллуром, остаётся стабильным после термообработки при $500^{\circ} \mathrm{C}$ в течение $10-20 \mathrm{~min}$. Следовательно, такой материал может быть использован в рамках современной планарной КМОП-технологии производства микросхем.

В настоящей работе исследовались структурные и оптические свойства кремния, гипердопированного селеном методом ионной имплантации с последующим импульсным лазерным отжигом (ИЛО). Оптимизация режимов ИЛО сможет обеспечить высокое структурное совершенство слоев кремния, имплантированных селеном $\left(\mathrm{Si}_{\mathrm{Se}}^{+}\right)$, и высокий коэффициент поглощения света в видимом и ИК диапазонах. На выявлении оптимальных условий лазерного отжига и сфокусированы рассматриваемые исследования.

\section{Методика эксперимента}

Образцы, вырезанные из пластин $\mathrm{Si} p$-типа с удельным сопротивлением $\rho=10 \mathrm{Ohm} \cdot \mathrm{cm}$ с термически выращенным слоем $\mathrm{SiO}_{2}$ толщиной $60 \mathrm{~nm}$ имплантировались ионами $\mathrm{Se}^{+}$при комнатной температуре в полиэнергетическом режиме. Энергия и флюенс ионов на первом и втором этапах имплантации составляли соответственно $220 \mathrm{keV}$ и $1.45 \cdot 10^{16}$ и $100 \mathrm{keV}, 5.12 \cdot 10^{15} \mathrm{ion} / \mathrm{cm}^{2}$. Такой выбор энергий и флюенсов ионов, смоделированный теоретически, обеспечивает более однородное распределение внедренной примеси по глубине. Тонкий слой $\mathrm{SiO}_{2}$ формировался для предотвращения потери внедренной примеси за счет диффузии через поверхность на этапе лазерных термообработок.

ИЛО исследуемых образцов $\mathrm{SiO}_{2} / \mathrm{Si}_{\mathrm{Se}}{ }^{+}$проводился при значениях плотности энергии $W=0.55,0.8,1,1.5,2$ и $2.5 \mathrm{~J} / \mathrm{cm}^{2}$ в наносекундном (75 ns) импульсе излучения рубинового лазера $(\lambda=694 \mathrm{~nm})$. Оптическая схема лазерной установки, на которой выполнен ряд предшествующих работ (см., например, [14]), обеспечивала высокую однородность распределения энергии импульса излучения лазера по зоне ИЛО размером $4 \times 4 \mathrm{~mm}$; отклонение в распределении плотности энергии падающего излучения относительно средней по лазерному пятну величины $W$, которая варьировалась калиброванными фильтрами из стекла НC, не превышало $\pm 5 \%$.

Оптическая диагностика in situ лазерно-индуцированных процессов в тестируемых образцах проводилась путём детектирования фотоприёмником (фотодиод ФД-256) зеркально отражённого от области ИЛО потока зондирующего излучения (ЗИ), источником которого являлся полупроводниковый лазер, работающий в непрерывном режиме генерации на длине волны $532 \mathrm{~nm}$. Мощность направленного в центральную область зоны ИЛО пучка ЗИ диаметром $\sim 1 \mathrm{~mm}$ (угол падения на образец 40) была менее $10 \mathrm{~mW}$. Выходной сигнал фотоприёмника (датчика ЗИ) подавался на вход цифрового осциллографа. Время нарастания переходной характеристики регистрирующего тракта фотоприёмник-осциллограф составляло 5-7 ns.

Оптическое поглощение $(A)$ в исследуемых слоях кремния рассчитывалось по спектрам пропускания $(T)$ и отражения $(R)$, измеренным в диапазоне $190-2400 \mathrm{~nm}$, по формуле

$$
A=100 \%-R-T \text {. }
$$

Спектры пропускания и отражения снимались на спектрометре Lambda 1050 WB (Perkin Elmer) как на 
образцах со слоем $\mathrm{SiO}_{2}$, так и после удаления его химическим стравливанием в растворе HF.

Анализ распределения концентрации атомов внедренной примеси по глубине, доли атомов селена в узлах кристаллической решетки кремния и степени кристалличности имплантированных слоев проводился методом регистрации спектров резерфордовского обратного рассеяния (POP) ионов $\mathrm{He}^{+}$с энергией $1.5 \mathrm{MeV}$ в режиме каналирования (channeling) вдоль направления $\langle 100\rangle$ и без него (random) на ускорительном комплексе HVE2500 с углом регистрации $170^{\circ}$. Информация о распределении концентрации атомов селена по глубине получена путем обработки спектров POP с использованием программного комплекса SIMNRA [15]. Моделирование спектров РОР с помощью этой программы проводилось ступенчато до полного совпадения с экспериментальными спектрами.

\section{Результаты и обсуждение}

В наших предыдущих исследованиях по формированию слоев кремния, гипердопированных примесями $\mathrm{Te}$ [6] и $\mathrm{Se}$ [5] при моноэнергетической имплантации ионов с флюенсами $1 \cdot 10^{16} \mathrm{ion} / \mathrm{cm}^{2}$ и энергией 200 и $125 \mathrm{keV}$ соответственно, установлено, что наиболее совершенному структурному состоянию легированных слоев соответствуют плотности энергии ИЛО 1.5, 2 и $2.5 \mathrm{~J} / \mathrm{cm}^{2}$. Значительное внимание в настоящей работе уделено оценке влияния этих режимов ИЛО на структурное состояние легированных слоев и уровень неравновесной растворимости атомов внедренной примеси. Для прикладной реализации сформированных структур в фотодетекторах ИК диапазона и высокоэффективных солнечных элементах на кремнии требование высокого структурного совершенства является обязательным с точки зрения генерации и переноса носителей тока. Интересно рассмотреть также режимы ИЛО с меньшей плотностью энергии в импульсе $\left(0.55,0.8\right.$ и $\left.1 \mathrm{~J} / \mathrm{cm}^{2}\right)$, при которых имплантированный слой переходит в расплавленное состояние полностью или только частично, и оценить, как это влияет на оптические свойства легированных слоев.

\section{Оптическая in situ диагностика процессов ИЛО}

Вначале рассмотрим особенности процессов, происходящих в приповерхностной области монокристалла кремния $(c-\mathrm{Si})$ при воздействии мощных лазерных импульсов наносекундной длительности. В результате такого воздействия в приповерхностном слое полупроводника генерируются электрон-дырочные пары с высокой плотностью (около $10^{20}-10^{21} \mathrm{~cm}^{-3}$ ). После этого в течение $10^{-11}-10^{-10} \mathrm{~s}$ происходит передача энергии возбужденных носителей решетке путем безызлучательной рекомбинации [16]. Такая теплопередача приводит к быстрому (около $10^{10} \mathrm{deg} / \mathrm{s}$ ) разогреву слоя поглощения, плавлению (фазовому переходу $c-\mathrm{Si} \rightarrow l-\mathrm{Si}$ ) и последующему резкому охлаждению из-за диффузии тепла в подложку. Эпитаксиальная кристаллизация $(l-\mathrm{Si} \rightarrow c-\mathrm{Si})$ в этом случае происходит из жидкой фазы послойно [16]. Толщина расплавленного слоя (глубина проплавления $d_{m}$ ) увеличивается с ростом плотности поглощенной энергии. Эпитаксиальный процесс $l$-Si $\rightarrow c$-Si в ситуации с ИЛО системы $\mathrm{SiO}_{2} / \mathrm{Si}: \mathrm{Se}^{+}$реализуется, если $d_{m}$ превышает исходную толщину $d_{a}$ ионно-аморфизированного слоя подложки.

В условиях ИЛО образца без плёнки $\mathrm{SiO}_{2}$ лазерноиндуцированное плавление $c$-Si (т.е. фазовый переход полупроводник $\rightarrow$ жидкий металл) достигается при достаточном превышении плотности энергии облучения $W$ над энергетическим порогом плавления $W_{m}$, составляющим около $1 \mathrm{~J} / \mathrm{cm}^{2}[14]$. При наибольшей в нашем эксперименте величине $W=2.5 \mathrm{~J} / \mathrm{cm}^{2}$ воздействием лазерного импульса (рис. 1, осциллограмма 1 ) инициируются фазовые переходы $l$-Si $\rightarrow c$-Si, продолжительность которых измеряется временем $\tau_{m}$ повышенного квазистационарного значения коэффициента отражения ЗИ $\left(R_{\max }\right)$ от зоны ИЛО (осциллограмма 2 ) и составляет $0.3 \mu \mathrm{s}$. На начальной стадии плавления величина $R(t)$ скачкообразно возрастает до указанного значения (за время $<20 \mathrm{~ns}$ ), которое определяется комплексным показателем преломления расплава, затем на заключительной стадии эпитаксиального процесса $R$ спадает за $60 \mathrm{~ns}$ и далее относительно медленно уменьшается по мере остывания нагретой области. Расчётная глубина проплавления образца $c$-Si в этой ситуации составляет $\sim 0.8 \mu \mathrm{m}$.

При ИЛО в одинаковом режиме $\left(W=2.5 \mathrm{~J} / \mathrm{cm}^{2}\right)$ зависимость $R(t)$ (осциллограмма 3) для системы $\mathrm{SiO}_{2} / \mathrm{Si}_{\mathrm{Se}}{ }^{+}$ значительно отличается от зависимости для $c-\mathrm{Si}$ (осц. 2). Отличается меньшими начальным и максимальным коэффициентами отражения ЗИ, почти четырёхкратным (т.е. более значительным) и длительным (более $100 \mathrm{~ns}$ ) возрастанием $R$ относительно исходного значения. Она отличается также почти трёхкратно большей длительностью лазерно-индуцированных фазовых превращений $(0.8 \mu \mathrm{s}$ против $0.3 \mu \mathrm{s})$, приводящих в эпитаксиальном процессе к образованию гипердопированного селеном слоя кремния при большей глубине проплавления подложки. Последовательное уменьшение задаваемого значения $W$ приводит к сокращению $\tau_{m}$ до $0.6 \mu \mathrm{s}\left(2 \mathrm{~J} / \mathrm{cm}^{2}\right.$, осц. 4), 0.4 (1.5, осц. 5) и $0.35 \mu \mathrm{s}\left(1 \mathrm{~J} / \mathrm{cm}^{2}\right.$, осц. 6). Последнее значение $\tau_{m}$ приближается к соответствующей длительности фазовых переходов, происходящих в $c$-Si (осц. 2) при отжиге в условиях значительно большей (в 2.5 раза) плотности энергии облучения образца. Понижение $W$ до 0.8 и $0.55 \mathrm{~J} / \mathrm{cm}^{2}$ приводит к сокращению длительности фазовых переходов до 0.2 и $0.1 \mu$ s соответственно (осц. 7 и 8 ) и их локализации в имплантированном слое $\left(d_{m}<d_{a}\right)$. При последовательном уменьшении плотности энергии от 2 до $0.55 \mathrm{~J} / \mathrm{cm}^{2}$ наблюдается снижение достигаемой в процессе плав- 


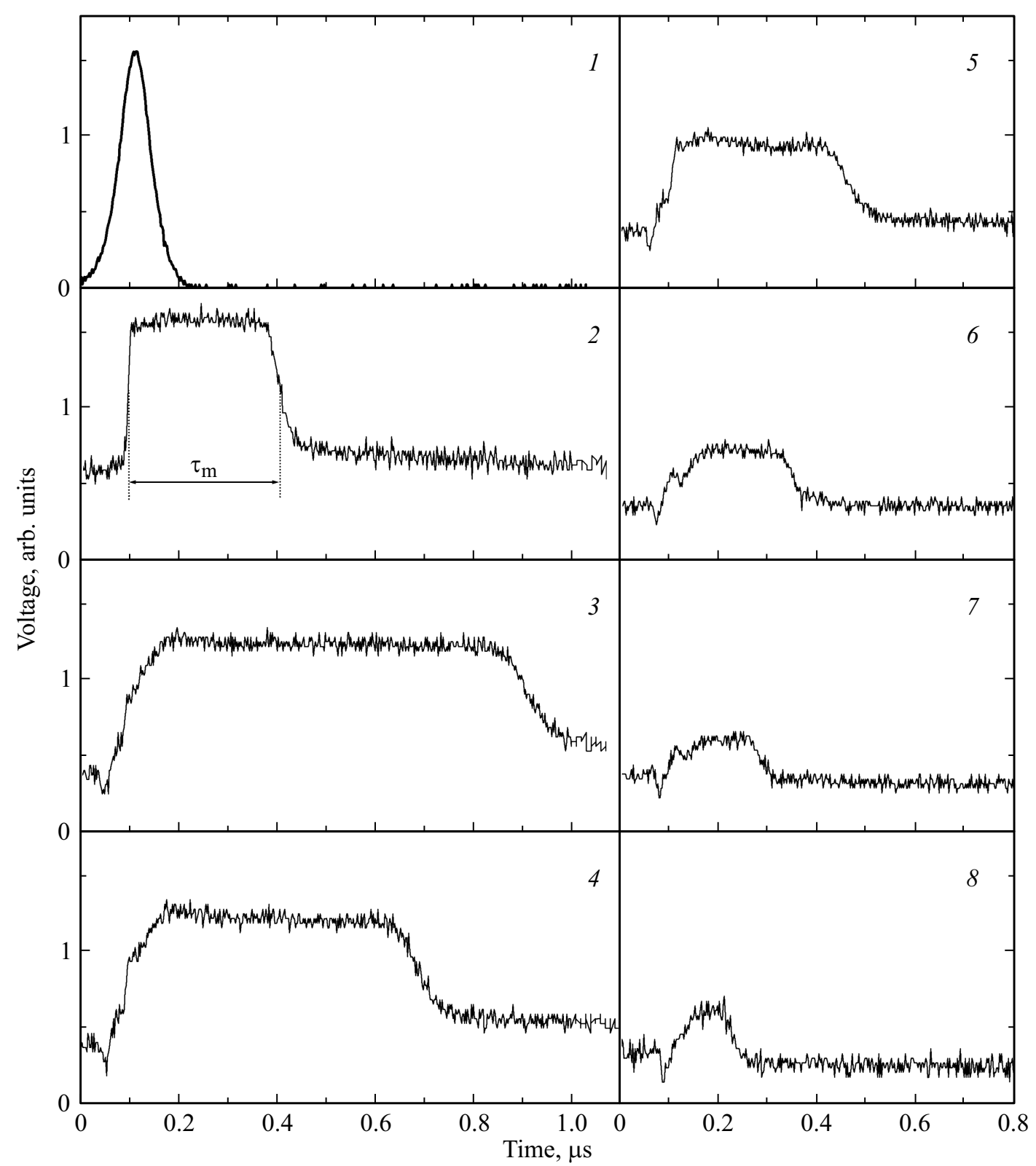

Рис. 1. Осциллограммы лазерного импульса $(1)$, воздействующего на образцы кремния и системы $\mathrm{SiO}_{2} / \mathrm{Si}_{\mathrm{Se}}^{+}$, и сигналов датчика зондирующего излучения, отражённого от зоны ИЛО $\mathrm{Si}\left(2, W=2.5 \mathrm{~J} / \mathrm{cm}^{2}\right)$ и $\mathrm{SiO}_{2} / \mathrm{Si}_{\mathrm{Se}}^{+}: W=2.5(3), 2.0$ (4), 1.5 (5), $1.0(6)$, $0.82(7)$ и $0.55 \mathrm{~J} / \mathrm{cm}^{2}(8)$.

ления $\mathrm{Si}$ под слоем $\mathrm{SiO}_{2}$ максимальной отражательной способности зоны ИЛО (т. е. $R_{\max }$ ).

Характерные особенности обсуждаемых процессов определяются тем, что при заданном флюенсе ионов $\mathrm{Se}^{+}$ (суммарный флюенс $2 \cdot 10^{16} \mathrm{ion} / \mathrm{cm}^{2}$ ) приповерхностная область кремния толщиной около $0.2 \mu \mathrm{m}$ [17] переходит в аморфное состояние. Теплофизические характеристики аморфного кремния $(a-\mathrm{Si})$ резко отличаются от таких же характеристик кристаллического материала. Это относится прежде всего к коэффициенту теплопроводности, который, как показали исследования [18], на порядок величины меньше у аморфного кремния. Кроме того, наблюдается снижение температуры плавления на $\sim 200 \mathrm{~K}[18,19]$. Эти факторы приводят к снижению пороговой плотности энергии для плавления $W_{m}$ примерно в 2 раза и увеличению толщины расплавленного слоя [18,20,21]. Поэтому эксперименты в настоящей работе выполнены и для плотностей энергии лазерного излучения $1,0.8$ и $0.55 \mathrm{~J} / \mathrm{cm}^{2}$, т.е. при пороговом значении $W \approx W_{m}$ для $c$-Si и ниже его. Минимальная в экспериментах величина плотности энергии $0.55 \mathrm{~J} / \mathrm{cm}^{2}$ превышает порог лазерно-индуцированного плавления слоя $a$-Si примерно на 10-15\%.

Пониженная на $\sim 200 \mathrm{~K}$ температура плавления $a$-Si в сравнении с $c$-Si обусловливает при достаточно высокой скорости нагрева, реализуемой в условиях ИЛО, об- 
разование метастабильной (значительно переохлаждённой) жидкой фазы, в которой возможно зарождение поликристаллической фазы. На стадии предплавления в аморфной фазе также вероятно возникновение промежуточных метастабильных состояний. Оба фактора могут приводить (рис. 1) к немонотонному (осц. 6 и 7) и более длительному в сравнении с ситуацией плавления $c-\mathrm{Si}$ (осц. 1) возрастанию отражательной способности образца и к начальному отрицательному скачку $R$, наблюдаемому во всех режимах ИЛО системы $\mathrm{SiO}_{2} / \mathrm{Si}_{:} \mathrm{Se}^{+}$(осц. 3-8) на начальной стадии действия лазерного излучения.

\section{Элементный состав и структура}

Спектры РОР в режимах random и channeling снимались на имплантированных селеном и отожженных образцах как со слоем $\mathrm{SiO}_{2}$, так и после его удаления. В качестве примера на рис. 2 приведены спектры POP для системы $\mathrm{SiO}_{2} / \mathrm{Si}_{\mathrm{Se}}^{+}$после ИЛО при однократном $(a)$ и трехкратном $(b)$ воздействии лазерного импульса плотностью энергии $2 \mathrm{~J} / \mathrm{cm}^{2}$. Как показывают результаты расчета, в исходном имплантированном образце концентрационный профиль характеризуется полочкообразным распределением с концентрацией на уровне $1.15 \cdot 10^{21}$ at. $/ \mathrm{cm}^{3}$ на глубинах $50-220 \mathrm{~nm}$ с резким спадом концентрации на глубинах $d>250 \mathrm{~nm}$ [22]. После ИЛО наблюдается перераспределение атомов примеси на глубины $d>400 \mathrm{~nm}$ с резким экспоненциальным спадом концентрации. Приповерхностной области характерно близкое к платообразному распределение концентрации, особенно в случае трех лазерных импульсов. Из-за наличия тонкого слоя $\mathrm{SiO}_{2}$, являющегося непрозрачным барьером для диффузии примеси, в приповерхностной области $\mathrm{SiO}_{2} / \mathrm{Si}$ формируется тонкий слой аккумулированного селена ( $\sim 5-7 \%$ от общего количества внедренных атомов).

На рис. 3 представлены спектры РОР в режимах random и channeling для имплантированных слоев после ИЛО при $W$ в диапазоне $0.55-02.5 \mathrm{~J} / \mathrm{cm}^{2}$. Соответствующие рассчитанные концентрационные профили представлены на рис. 4. После ИЛО (рис. 4) форма концентрационных распределений атомов селена существенно зависит от плотности энергии лазерного импульса. Можно выделить две градации таких профилей, характерных плотностям энергий $0.55,0.8,1 \mathrm{~J} / \mathrm{cm} 2$ и $1.5,2$ и $2.5 \mathrm{~J} / \mathrm{cm}^{2}$. При плотностях энергии ИЛО $0.55-1.0 \mathrm{~J} / \mathrm{cm}^{2}$ диффузионное перераспределение атомов селена незначительно. В частности, концентрационный профиль $N(x)$ ( $N$ - концентрация атомов, $x-$ глубина $)$ для $W=0.55 \mathrm{~J} / \mathrm{cm}^{2}$ мало отличается от соответствующего профиля для неотожженного образца. В случае ИЛО с плотностями энергии $1.5-2.5 \mathrm{~J} / \mathrm{cm}^{2}$ на глубинах 30-150 nm формируется платообразное распределение селена в диапазоне концентраций $(9-8) \cdot 10^{20} \mathrm{at} . / \mathrm{cm}^{3}$, сопровождающееся длинными диффузионными хвостами до глубин 500-600 nm. Эти особенности двух вариантов концентрационных распределений следует отнести к влиянию толщины расплавленных слоев и времени жизни жидкой фазы кремния как функции плотности энергии лазерного импульса [5]. Диффузионные коэффициенты примесей в жидком $D_{\text {liq }}$ и твердом $D_{\text {sol }}$ состояниях кремния отличаются на много порядков величины, и для атомов селена $D_{\text {liq }} \approx 1.4-2.9 \cdot 10^{-4} \mathrm{~cm}^{2} / \mathrm{c}[23]$.

Процесс диффузионного перераспределения имплантированных атомов халькогенов в жидком слое кремния, инициированном поглощенной энергией лазерного импульса, а также на стадии остывания слоя в твердом состоянии теоретически описан нами в работе [5].

Для оценки степени кристалличности легированного слоя кремния и определения доли атомов $\mathrm{Se}$ в узлах кристаллической решетки $\mathrm{Si}$ использованы величины $\chi^{\mathrm{Si}}$ и $\chi^{\mathrm{Se}}$, извлекаемые из спектров РОР, снятых в режиме каналирования. Данные величины представляют собой интегральные отношения отсчетов каналированного к случайному спектру в каналах, связанных со слоем имплантированного $\mathrm{Si}$ (левая часть спектров) и $\mathrm{Se}$ (правая часть спектров) соответственно (рис. 2). При этом у идеального монокристалла $\chi_{\min }^{\mathrm{Si}} \leq 5 \%$, а у полностью аморфизованного материала $\chi^{\mathrm{Si}}=100 \%$ [24,25].

Кратко поясним сущность используемой методики. Когда пучок зондирующих ионов $\mathrm{He}^{+}$падает на кристалл параллельно какой-либо кристаллографической оси (в нашем случае $\langle 100\rangle \mathrm{Si}$ ), на входе он разделяется на две компоненты: каналированную и хаотическую. Каналированные ионы не подходят к цепочке атомов ближе некоторого расстояния $r_{\min }$. Согласно теории Линдхарда [18],

$$
r_{\min }^{2}=U_{\perp}^{2}+a^{2},
$$

где $U_{\perp}-$ амплитуда тепловых колебаний атомов перпендикулярно рассматриваемой цепочке, $a$ - параметр экранировки по Фирсову [18]:

$$
a=\frac{0.8853 a_{0}}{\left(z_{1}^{1 / 2}+z_{2}^{1 / 2}\right)^{2 / 3}},
$$

$z_{1}, z_{2}$ - атомные номера налетающего иона и атомов мишени; $a_{0}=0.053 \mathrm{~nm}$ - боровский радиус атома водорода. Если примесные атомы находятся в замещающем состоянии внутри области $r_{\min }$, то отношение числа регистрируемых частиц при каналировании к числу их при неориентированном облучении,

$$
Y_{\mathrm{ch}} / Y_{r} \approx \pi r_{\min }^{2} N d \approx 0.02-0.05
$$

примерно равно доле ионов $\mathrm{He}^{+}$, не попадающих в каналы с самого начала $(N-$ число атомов в единице объема, $d$ - межатомное расстояние в атомной цепочке). Следовательно, если примесные атомы локализованы внутри области $r_{\min }$, происходит сильное уменьшение выхода $Y_{\text {ch }}$ при каналировании (примерно на 2 порядка величины) по сравнению со случаем облучения неориентированной мишени. При наличии дефектов структуры 

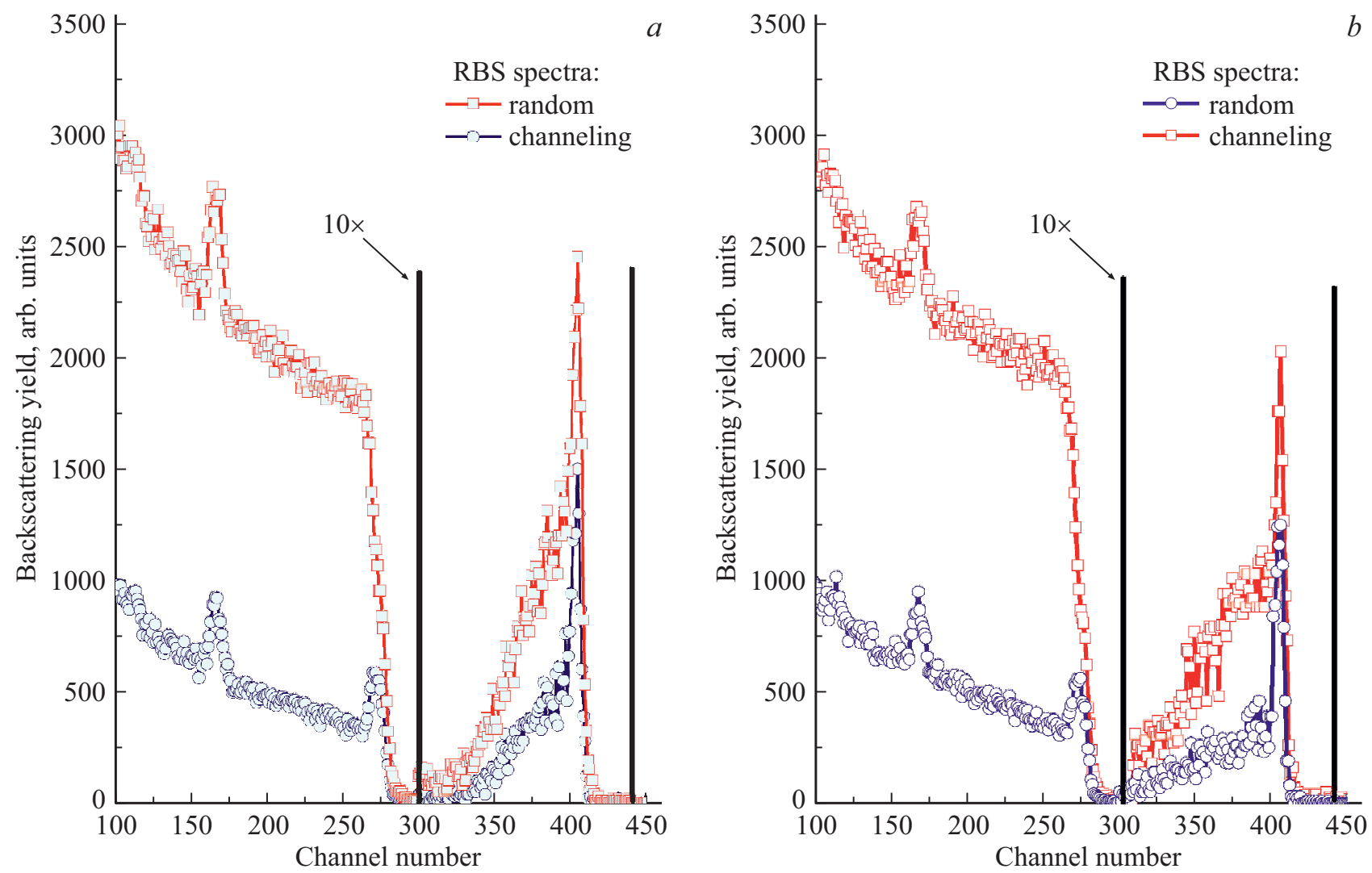

Рис. 2. Случайные и каналированные спектры $\mathrm{POP}$ от структуры $\mathrm{SiO}_{2}(60 \mathrm{~nm}) / \mathrm{Si}$ после двойной имплантации ионов селена $\left(220 \mathrm{keV}, 1.45 \cdot 10^{16} \mathrm{~cm}^{-2}+100 \mathrm{keV}, 5.12 \cdot 10^{15} \mathrm{~cm}^{2}\right)$ и лазерного отжига: $a-2 \mathrm{~J} / \mathrm{cm}^{2}, 1$ импульс, $b-2 \mathrm{~J} / \mathrm{cm}^{2}, 3$ импульса.

в легированном слое это отношение возрастает. Типы дефектов и их концентрации определяют величину рассматриваемого отношения. В интегральных по толщине легированного слоя значениях $Y$, т. е. $\chi^{\mathrm{Si}}, \chi^{\mathrm{Se}}$, и заложена обсуждаемая информация.

В нашем случае (по данным РОР) высокодозная имплантация ионов $\mathrm{Se}^{+}$приводит к аморфизации слоя кремния толщиной $\approx 0.2 \mu \mathrm{m}$. Как свидетельствует спектр РОР из рис. $4, a$, ИЛО при $W=0.55 \mathrm{~J} / \mathrm{cm}^{2}$ не приводит к эпитаксиальной перекристаллизации всего легированного слоя $\mathrm{Si}$.

Степень кристалличности слоев легированного кремния $f_{\text {cr }}$ определялась из выражения [24]

$$
f_{\text {cr }}=\frac{1-\chi^{\mathrm{Si}}}{1-\chi_{\min }},
$$

а доля атомов примеси в узлах кристаллической решетки $f_{\text {subst }}$ рассчитывалась в соответствии с формулой [24]

$$
f_{\text {subst }}=\frac{1-\chi^{\mathrm{Se}}}{1-\chi_{\min }} .
$$

Как следует из данных таблицы, только при плотностях энергии ИЛО $\geq 0.8 \mathrm{~J} / \mathrm{cm}^{2}$ наблюдается заметное восстановление кристаллической решетки и достаточно высокая неравновесная растворимость атомов селена в кремнии. Оптимальной с позиции структурного совершенства $(91.6 \%)$ и максимальной концентрации Se в замещающем положении в решетке $\mathrm{Si}(65.6 \%)$ является плотность энергии $W=2 \mathrm{~J} / \mathrm{cm}^{2}$. Высокая концентрация примесных атомов (халькогенов), занимающих узловые положения, играет ключевую роль в оптическом поглощении как в видимом, так и ИК диапазоне [1-3,5-7].

Оценим возможность формирования примесной подзоны в зоне проводимости кремния при полученных уровнях концентрации селена в замещающих состояниях в решетке $\mathrm{Si}$. Средняя концентрация атомов селена в слое кремния толщиной $400 \mathrm{~nm}$ для ИЛО при $W=2 \mathrm{~J} / \mathrm{cm}^{2}$ в соответствии с данными рис. 2 составляет $\sim 4 \cdot 10^{20}$ at. $/ \mathrm{cm}^{3}$ (0.8 at.\%); замещающая фракция селена (таблица) в этом случае составляет $2.62 \cdot 10^{20}$ at. $/ \mathrm{cm}^{3}$ (0.52 at.\%). Остальная часть внедренной примеси находится в виде многоатомных кластеров [26].

В соответствии с теорией Мотта [27] критическая концентрация донорных электронов $N^{\text {cr }}$ для осуществления перехода диэлектрик-металл в полупроводниках может быть оценена из выражения

$$
N^{\mathrm{cr}}=\left(\frac{c}{a_{\mathrm{H}}}\right)^{3},
$$

где $c=0.25$ - константа, $a_{\mathrm{H}}-$ радиус Бора донорных электронов. Величина радиуса Бора может быть пред- 

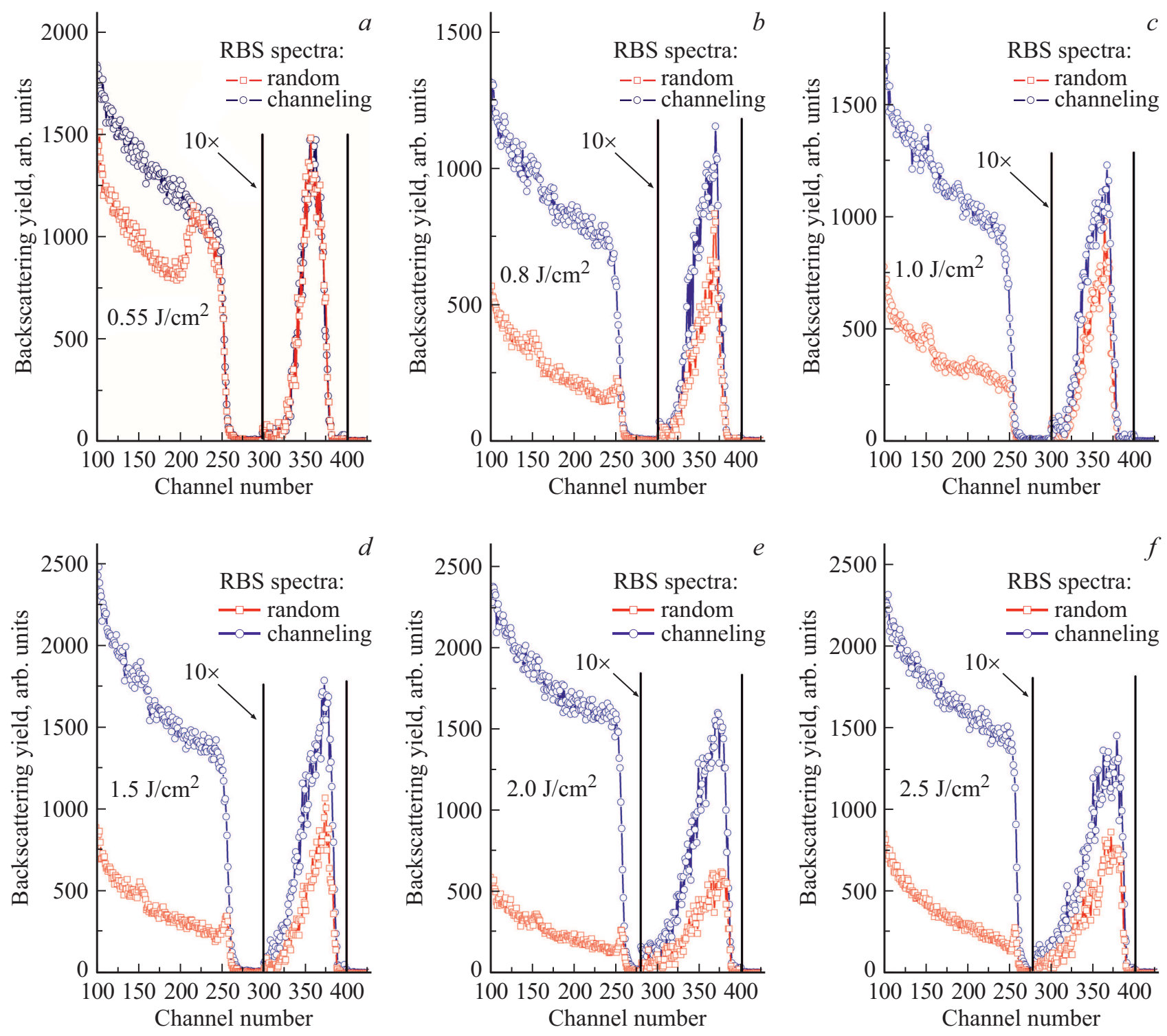

Рис. 3. Случайные и каналированные спектры POP от слоев кремния после двойной имплантации ионов селена (220 keV, $\left.1.45 \cdot 10^{16} \mathrm{~cm}^{-2}+100 \mathrm{keV}, 5.12 \cdot 10^{15} \mathrm{~cm}^{-2}\right)$ и лазерного отжига.

ставлена как

$$
a_{\mathrm{H}}=\frac{e^{2}}{8 \pi \varepsilon_{0} \varepsilon_{r} E_{d}},
$$

где $e$ - заряд электрона, $\varepsilon_{0}$ - диэлектрическая проницаемость вакуума, $\varepsilon_{r}$ - высокочастотная диэлектрическая постоянная кремния, $E_{d}-$ энергия активации локализованных состояний. Тогда, учитывая величину энергия активации $E_{d}=0.307 \mathrm{eV}$ для атомов селена в решетке кремния [28], изотропный радиус Бора в соответствии с критерием Мотта составляет $2.02 \AA$. Следовательно, критическая концентрация электронов для обеспечения перехода изолятор-металл в гипердопированном селеном кремнии приблизительно равна $1.91 \cdot 10^{21} \mathrm{~cm}^{-3}$, что соответствует концентрации атомов Se $9.5 \cdot 10^{20} \mathrm{~cm}^{-3}$, так как каждый замещающий атом Se является двойным донором. Для полученного в настоящей работе уровня легирования кремния $\left(2.62 \cdot 10^{20} \mathrm{~cm}^{-3}\right)$ этот переход еще не достигается.

Высокой концентрации замещающего селена соответствует определенная ширина примесной подзоны [29]

$$
\Delta E_{\mathrm{IB}}=\frac{e^{2} N^{1 / 3}}{4 \pi \varepsilon_{0} \varepsilon_{r}} .
$$

Для уровня легирования кремния селеном, достигнутого при ИЛО с $W=2 \mathrm{~J} / \mathrm{cm}^{2}$, в соответствии с выражением (8) получаем $\Delta E_{\mathrm{IB}} \approx 0.1 \mathrm{eV}$. Строгие расчеты из первых принципов на основе теории функционала плотности [30] для кремния с близким уровнем легирования селеном ( 1 атом селена на 215 атомов кремния, что соответствует $2.33 \cdot 10^{20} \mathrm{~cm}^{-3}$ ) ширину примесной подзоны определяют в $0.22 \mathrm{eV}$. Она располагается на расстоянии $\approx 0.4 \mathrm{eV}$ от валентной зоны $\Delta E(\mathrm{VB}-\mathrm{IB})$ 
Степень кристалличности слоев кремния $\left(f_{\text {cr }}\right)$ и доля примеси в узлах кристаллической решетки $\left(f_{\text {subst }}\right)$ после двойной имплантации ионов селена $\left(220 \mathrm{keV}, 1.45 \cdot 10^{16} \mathrm{~cm}^{-2}+100 \mathrm{keV}, 5.12 \cdot 10^{15} \mathrm{~cm}^{-2}\right)$ и различных режимов лазерного отжига

\begin{tabular}{c|c|c|c|c|c|c}
\hline \multirow{2}{*}{$\begin{array}{c}\text { Режим } \\
\text { ИЛО, } \\
\mathrm{J} / \mathrm{cm}^{2}\end{array}$} & \multicolumn{3}{|c|}{ Выход от кремния } & \multicolumn{3}{c}{ Выход от селена } \\
\cline { 2 - 7 } & каналы & $1-\chi^{\mathrm{Si}}$ & $\begin{array}{c}f_{\text {cr }}= \\
\left(1-\chi^{\mathrm{Si}}\right) /\left(1-\chi_{\text {min }}\right), \%\end{array}$ & каналы & $1-\chi^{\mathrm{Se}}$ & $\begin{array}{c}f_{\text {subst }}= \\
\left(1-\chi^{\mathrm{Se}}\right) /\left(1-\chi_{\text {min }}\right), \%\end{array}$ \\
\hline 1 & 2 & 3 & 4 & 5 & 6 & 7 \\
\hline 0.55 & $150-275$ & 0.215 & 22.6 & $300-400$ & 0.017 & 1.79 \\
0.8 & $150-275$ & 0.719 & 75.7 & $300-400$ & 0.424 & 44.6 \\
1.0 & $150-275$ & 0.684 & 72.0 & $300-400$ & 0.360 & 37.9 \\
1.5 & $150-275$ & 0.777 & 81.8 & $300-400$ & 0.526 & 55.4 \\
2.0 & $150-275$ & 0.870 & 91.6 & $300-400$ & 0.623 & 65.6 \\
2.5 & $150-275$ & 0.823 & 86.6 & $300-400$ & 0.471 & 49.6
\end{tabular}

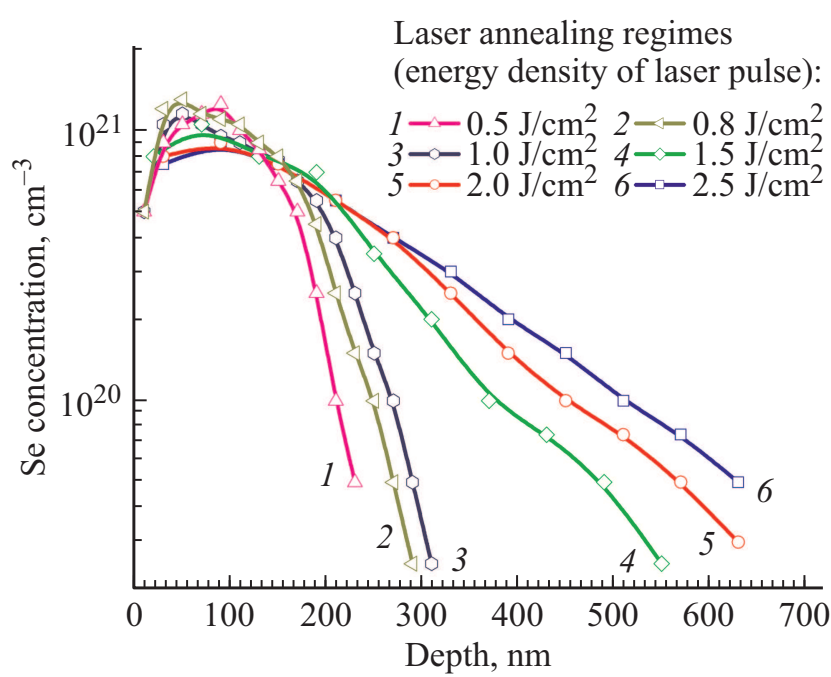

Рис. 4. Концентрационные профили атомов селена в слоях кремния после двойной ионной имплантации $(220 \mathrm{keV}$, $\left.1.45 \cdot 10^{16} \mathrm{~cm}^{-2}+100 \mathrm{keV}, 5.12 \cdot 10^{15} \mathrm{~cm}^{-2}\right)$ и лазерного отжига в различных режимах.

и на расстоянии $\sim 0.50 \mathrm{eV}$ от зоны проводимости $\Delta E$ (IB-CB).

\section{Оптические свойства}

На рис. 5 представлены спектры пропускания, зеркального отражения и поглощения. Лазерный отжиг имплантированных слоев кремния приводит к резкому уменьшению пропускания кремневых пластин на $30-40 \%$ (рис. 5, $a$ ). Причем с увеличением плотности энергии лазерного импульса пропускание уменьшается.

Лазерный отжиг также приводит к снижению отражения в ИК области (на 4-10\%), однако зависимость отражения от плотности энергии лазерного импульса более сложная (рис. 5,b). Для образца сразу после имплантации, а также для образцов, отожженных при меньших плотностях энергии $W=0.55$ и $0.8 \mathrm{~J} / \mathrm{cm}^{2}$, проявляются интерференционные максимумы и минимумы.
Для исходного образца максимум и минимум также регистрируются и в спектре пропускания: максимум в проходящем свете соответствует минимуму в отраженном и наоборот. Естественно предполагать, что интерференция происходит в тонком аморфном сильнолегированном слое кремния. После отжига при $W=0.55 \mathrm{~J} / \mathrm{cm}^{2}$ в спектрах отражения максимумы/минимумы незначительно сдвигаются в длинноволновую область, а также уменьшается разность между значениями отражения в максимуме и минимуме (интерференция ослабевает). Увеличение энергии лазерного импульса $\left(0.8,1.0 \mathrm{~J} / \mathrm{cm}^{2}\right)$ приводит к усилению данного эффекта. Это можно объяснить увеличением толщины интерференционного слоя и уменьшением показателя преломления. Увеличение толщины интерференционного слоя с увеличением энергии лазерного импульса соответствует увеличению толщины легированного слоя по данным РОР. При бо́льших плотностях энергии ИЛО характерных интерференционных полос в спектрах отражения уже не наблюдается. При плотности энергии ИЛО $W \geq 1 \mathrm{~J} / \mathrm{cm}^{2}$ в спектрах отражения проявляется узкая полоса при $370 \mathrm{~nm}$, соответствующая критической точке зонной структуры кремния, что свидетельствует о восстановлении кристаллической структуры имплантированного слоя. Стоит отметить более существенное уменьшение отражения в видимой области после ИЛО (на 15-50\%). Причем наименьшая величина отражения в видимой области регистрируется для образцов, облученных лазерным импульсом при небольших энергиях $\left(0.55\right.$ и $\left.0.8 \mathrm{~J} / \mathrm{cm}^{2}\right)$.

В совокупности уменьшение отражения, а в большей степени пропускания после лазерного отжига приводит к увеличению поглощения в ИК области спектра, что представлено на рис. 5,c. Как видно, лазерный отжиг приводит к увеличению ИК поглощения имплантированного слоя на 36-40\%. Наибольшим поглощением характеризуется образец после ИЛО при $W=1 \mathrm{~J} / \mathrm{cm}^{2}$. Дополнительно, с учетом глубины залегания примесей, полученной из данных РОР, были рассчитаны спектры коэффициента поглощения в ИК области для образцов после ИЛО. Они представлены на рис. 5, $d$. Как видно, имплантация кремния селеном в сочетании с ИЛО 

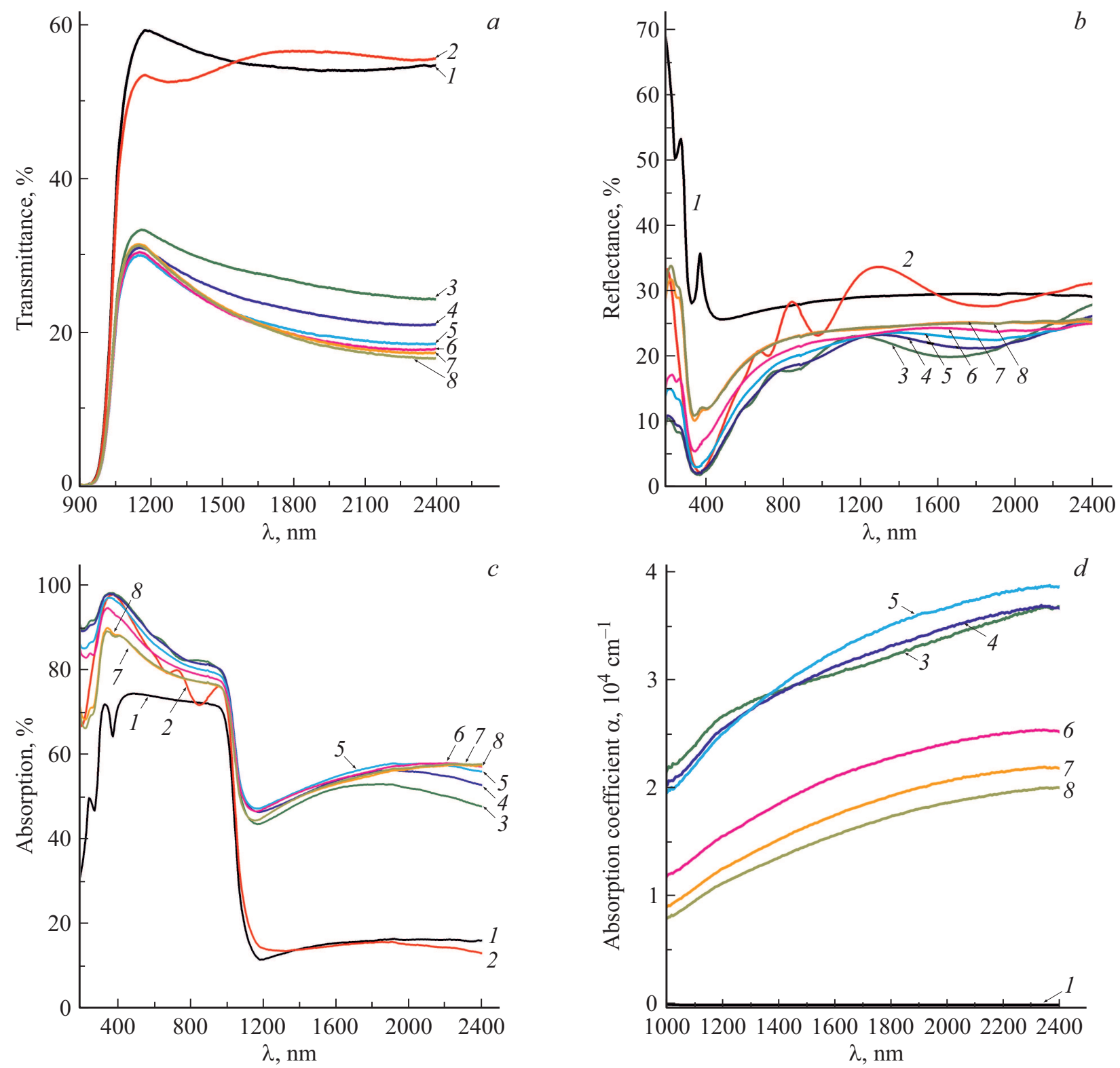

Рис. 5. Спектры пропускания $(a)$, отражения $(b)$, поглощения $(c)$ и коэффициента поглощения $(d)$ до и после имплантации и ИЛО при разных плотностях энергии импульса: $1-\mathrm{SiO}_{2} / \mathrm{Si}, 2-\mathrm{SiO}_{2} / \mathrm{Si}_{\mathrm{Se}}{ }^{+}, 3-0.55 \mathrm{~J} / \mathrm{cm}^{2}, 4-0.8 \mathrm{~J} / \mathrm{cm}^{2}, 5-1.0 \mathrm{~J} / \mathrm{cm}^{2}, 6-$ $1.5 \mathrm{~J} / \mathrm{cm}^{2}, 7-2.0 \mathrm{~J} / \mathrm{cm}^{2}, 8-2.5 \mathrm{~J} / \mathrm{cm}^{2}$.

приводит к возрастанию коэффициента поглощения на 4 порядка. Наибольшим коэффициентом поглощения характеризуются слои, отожженные при плотностях энергии $0.55-1.5 \mathrm{~J} / \mathrm{cm}^{2}$, что связано с меньшей толщиной легированного слоя (большей концентрацией в максимуме) по сравнению с образцами после ИЛО при больших плотностях энергии 2 и $2.5 \mathrm{~J} / \mathrm{cm}^{2}$.

Поглощение в видимой области рассчитано только на основе данных отражения, так как пропускание кремниевой пластины в данной области нулевое. Как видно, имплантация ионов селена, сопровождающаяся аморфизацией слоя кремния толщиной около $0.2 \mu \mathrm{m}$, без лазерной обработки приводит к усилению поглощения в видимой области. Лазерный отжиг при плотностях энер- гии $W=0.5-1.5 \mathrm{~J} / \mathrm{cm}^{2}$ усиливает этот эффект, тогда как отжиг при $W=2$ и $2.5 \mathrm{~J} / \mathrm{cm}^{2}$ ослабляет его. Вероятнее всего в данном случае увеличение поглощения связано с аморфизацией приповерхностного слоя [31].

Для наглядности на рис. 6 приведена зависимость интегрального поглощения от плотности энергии в лазерном импульсе. Как видно, уже после отжига при наименьшей плотности энергии $\left(0.55 \mathrm{~J} / \mathrm{cm}^{2}\right)$ поглощение достаточно большое, несмотря на низкий уровень восстановления кристаллической решетки кремния $\left(f_{\mathrm{Si}}=22.6 \%\right)$ и вхождения атомов $\mathrm{Se}$ в узлы решетки $\left(f_{\mathrm{Se}}=1.8 \%\right)$. Дальнейшая зависимость от энергии лазерного отжига немонотонная: максимум ИК поглощения наблюдается после отжига при $W=1 \mathrm{~J} / \mathrm{cm}^{2}$, а 


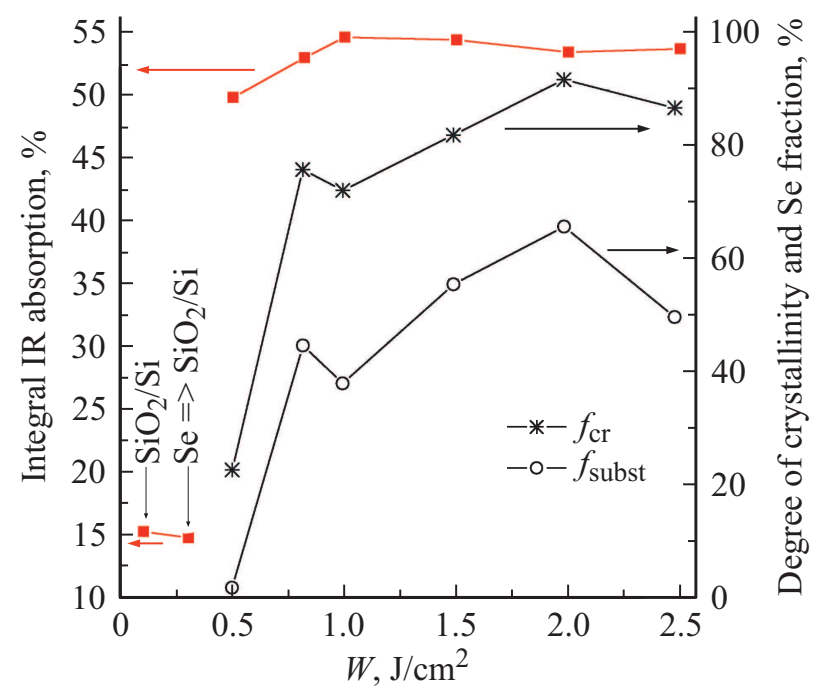

Рис. 6. Зависимости интегрального поглощения в спектральной области 0.9-2.4 $\mu \mathrm{m}$, степени кристалличности имплантированных слоев кремния $\left(f_{\text {cr }}\right)$ и доли примеси в узлах кристаллической решетки $\left(f_{\text {subst }}\right)$ от плотности энергии ИЛО.

при дальнейшем увеличении плотности энергии лазерного импульса поглощение незначительно снижается. Стоит отметить, что для образцов, облученных лазерным импульсом с плотностью энергии $0.8 \mathrm{~J} / \mathrm{cm}^{2}$ и выше, наблюдается обратная зависимость ИК поглощения от $f_{\mathrm{Si}}$ и $f_{\mathrm{Se}}$.

Дополнительно был оценен эффект тонкой оксидной пленки $(<60 \mathrm{~nm})$ на оптические свойства имплантированных слоев. Удаление данного слоя проявлялось в существенном увеличении отражения в видимой области (до 24\%). В ИК области данный эффект выражен существенно слабее, но также присутствует: при удалении оксидного слоя ИК отражение увеличивается в среднем на $1.5-2.5 \%$. Таким образом, тонкий слой оксида является не только барьером для диффундирующих примесей, но и антиотражающим покрытием, полезным как для элементов солнечной энергетики, так и для кремниевых фотодетекторов.

\section{Заключение}

Представлены экспериментальные данные, полученные методом in situ, характеризующие динамику лазерно-индуцированных процессов модификации структурного состояния имплантированных селеном слоёв кремния в системе $\mathrm{SiO}_{2} / \mathrm{Si}$. Методом полиэнергетической ионной имплантации селена с последующим импульсным лазерным отжигом удалось увеличить коэффициент поглощения кремния в ИК диапазоне на 4 порядка. Анализ структуры имплантированных слоев, облученных лазерными импульсами при плотностях энергии в импульсе от 0.55 до $2.5 \mathrm{~J} / \mathrm{cm}^{2}$, показал, что наибольшей доли примеси в узлах кристаллической решетки
Si (65.6\%), а также наибольшей степени восстановления кристаллической структуры имплантированного слоя удается достичь после ИЛО при $W=2 \mathrm{~J} / \mathrm{cm}^{2}$. Оптическое поглощение в ИК области резко увеличивается (на 35\%) даже после ИЛО при минимальной $W=0.5 \mathrm{~J} / \mathrm{cm}^{2}$. Увеличение плотности энергии в лазерном импульсе приводит к незначительному изменению ИК поглощения (в пределах 5\%). Наибольшим поглощением характеризуются слои после ИЛО при плотности энергии $1 \mathrm{~J} / \mathrm{cm}^{2}$. Таким образом, в случае слоев кремния, гиперпересыщенных атомами селена (до концентраций $10^{21}$ атомов $\left./ \mathrm{cm}^{3}\right)$, поглощение, строго говоря, не коррелирует со степенью внедрения примеси в узлы и уровнем восстановления кристаллической решетки имплантированного слоя.

\section{Финансирование работы}

Работа выполнялась в рамках государственной программы научных исследований „Фотоника и электроника для инноваций“.

\section{Конфликт интересов}

Авторы заявляют, что у них нет конфликта интересов.

\section{Список литературы}

[1] Luque A., Marti A., Stanley C. // Nature Photonics. 2012. V. 6. P. 146. doi 10.1038/nphoton.2012.1

[2] Carey J.E., Crouch C.H., Shen M., Mazur E. // Opt. Lett. 2005. V. 30. P. 1773. doi 10.1364/OL.30.001773

[3] Umezu I., Warrender J.M., Charnvanichborikarm S. // J. Appl. Phys. 2013. V. 113. P. 213501. doi 10.1063/1.4804935

[4] Schibli E., Milnes A.G. // Materials Science and Engineering. 1967. V. 2. P. 173. doi 10.1016/0025-5416(67)90056-0

[5] Komarov F.F., Ivlev G., Zayats G. Komarov A., Nechaev N., Parkhomenko I., Vlasukova L., Wendler E., Miskiewicz S. // Acta Physica Polonica. 2019. V. 136. N 2. P. 254. doi 10.12693/APhysPolA.136.254

[6] Komarov F.F., Nechaev N.S., Ivlev G., Vlasukova L.A., Wendler E., Romanov I.F., Berencén Y., Pilko V.V., Zhigulin D.V., Komarov A.F. // Vacuum. 2020. V. 178. P. 109434. doi 10.1016/j.vacuum.2020.109434

[7] Berencén Y., Prucnal S., Liu F., Skorupa I., Hübner R. // Scientific Reports. 2017. V. 7. N 1. P. 43688. doi 10.1038/srep43688

[8] Shockley W., Queisser H.J. // J. Appl. Phys. 1961. V. 32. N 3. P. 510. doi 10.1063/1.1736034

[9] Luque A., Martí A. // Phys. Rev. Lett. 1997. V. 78. N 26. P. 5014. doi 10.1103/PhysRevLett.78.5014

[10] Gossmann H.-J., Rafferty C.S., Keys P. // MRS Proceedings. 1999. V. 610. P. B1.2.1. doi 10.1557/PROC-610-B1.2

[11] Gossmann H.J., Unterwald F.C., Luftman H.S. // J. Appl. Phys. 1993. V. 73. N 12. P. 8237. doi $10.1063 / 1.353441$

[12] Wang M., Berencén Y., Garcia-Hemme E., Prusnal S., Hubner R., Yuan Y., Xu C., Rebohle L., Bottger R., Heller R., Skorupa W., Helm M., Zhou S. // Phys. Rev. Appl. 2018. V. 10. P. 024054. doi 10.1103/PhysRevApplied.10.024054 
[13] Wang M., Berencén Y. // Phys. Stat. Sol. 2020. V. A2020. P. 2000260. doi 10.1002/pssa.202000260

[14] Ivlev G.D., Gatskevich E.I. // Tech. Phys. 2012. V. 57. P. 803. doi 10.1134/S1063784212060138

[15] Mayer M. SIMNRA User's Guide. Max-Planck-Institute fur Plasmaphysik, Garching, 1997. 62 p.

[16] Комаров Ф.Ф., Новиков А.Н., Соловьев В.С., Ниряев С.Ю. Дефекты структуры в ионно-имплантированном кремнии. Минск: Университетское, 1990. $320 \mathrm{c.}$

[17] Буренков А.Ф., Комаров Ф.Ф., Кумахов М.А., Темкин М.М. Пространственные распределения энергии, выделенной в каскаде атомных столкновений в твердых телах. М.: Энергоатомиздат, 1985. $246 \mathrm{c.}$

[18] Комаров Ф.Ф., Комаров А.Ф. Физические процессы при ионной имплантации в твердые тела. Минск: Технопринт, 2001. $394 \mathrm{c}$.

[19] Thompson M.O., Galvin J.G., Mayer J.W., Peercy P.S., Poate J.M., Jacobson D.C., Cullis A.G., Chew N.G. // Phys. Rev. Lett. 1984. V. 52. P. 2360. doi 10.1103/PhysRevLett.52.2360

[20] Двуреченский А.В., Качурин Г.А., Нидаев Е.В., Смирнов Л.С. Импульсный отжиг полупроводниковых материалов. М.: Наука, 1982. 208 с.

[21] Борисенко B.E. Твердофазные процессы в полупроводниках при импульсном нагреве. Минск: Навука і тэхніка, 1992. 248 c.

[22] Komarov A.F., Komarov F.F., Żukowski P., Karwat C., Shukan A.L. // Nukleonika. 1999. V. 44. P. 363.

[23] Bob B.P., Kohno A., Charnvanichborikarm S., Warrender J.M., Umezu I., Tabbal M., Williams J.S., Aziz M.J. // J. Appl. Phys. 2010. V. 107. P. 123506. doi 10.1063/1.3415544

[24] Feldman L.C., Mayer W., Picraux S.T. Materials Analysis by Ion Channeling: Submicron Crystallography. NY: Academic Press, 1982. $356 \mathrm{p}$.

[25] Komarov F.F., Kumakhov M.A., Tashlykov I.S. Nondestructive Ion Beam Analysis of Surfaces. NY: Gordon and Breach Sci. Publ., 1990. 232 p.

[26] Zhou Sh., Liu F., Prucnal S., Gao K., Khalid M., Baehtz C., Posselt M., Skorupa W., Helm M. // Scientific Reports. 2015. V. 5. N 10. P. 08329. doi 10.1038/srep08329

[27] Mott N.F. // Contemp. Phys. 1973. V. 14. P. 401. doi $10.1080 / 00107517308210764$

[28] Jansèn E., Stedman R., Grossmann G., Grimmeiss H.G. // Phys. Rev. B. 1984. V. 29. P. 1907. doi 10.1103/PhysRevB.29.1907

[29] Schubert E.F. Doping III-V Semiconductors. Cambridge: University Press, 1993. 354 p.

[30] Sánchez K., Aguilera I., Palacios P., Wahnón P. // Phys. Rev. B. 2010. V. 82. P. 165201. doi 10.1103/PhysRevB.82.165201

[31] Иго А.В. // Опт. и спектр. 2020. Т. 128. № 8. С. 1115; Igo A.V. // Opt. Spectrosc. 2020. V. 128. N 8. P. 1125. doi 10.1134/S0030400X20080135 